\title{
Ejaculation malfunctions on the day of oocyte pick up for IVF/ICSI: A report of four cases
}

\author{
${ }^{1}$ Aamir Javed, ${ }^{1}$ Ashwini LS, ${ }^{2}$ Vijaya Geetha Pathangae, ${ }^{2}$ Ashim Roy, \\ ${ }^{3}$ Debashree Ganguly \\ ${ }^{1}$ Department of Embryology, Base Fertility Medical Science Pvt Ltd, India. \\ ${ }^{2} R$ \& D in Life Sciences, Dayananda Sagar Institutions, India. \\ ${ }^{3}$ Jahar Infertility Research Institute, India
}

*Corresponding author: Javed Aamir, Department of Embryology, BFMS, KHB Colony,

Basaveshwarnagar, Bangalore - 79, India.

Email: javed.aamir7700@gmail.com

Keywords: Ejaculation malfunctions; IVF/ICSI

\begin{abstract}
\section{Introduction:}

The procedure of in-vitro fertilization (IVF) is sometime physically stressful and emotional turmoil on the couples undergoing treatment. The male partner is obliged to produce semen for injection/insemination with the oocytes. Unfortunately, some men are ill-fated, not capable to reproduce semen on the day of oocyte pickup.
\end{abstract}

Objective: To testify four cases of unexpected ejaculation malfunction on the day of oocyte pickup.

Setting: Base Fertility Medical Science Pvt Ltd.

Materials and method: The case retrospectively reviewed the case records of four couples over a year period (September 2013-November 2014), who suffered unexpected ejaculation complete failure on the day of oocyte pickup for IVF/ICSI. Data, including age, Stimulation Protocol, cause(s) of infertility, previous treatment history (If Any) and various techniques implemented to retrieve sperms were documented.

Results: Altogether, 362 oocyte pickup cycles were conducted during a year period. Four men had ejaculatory failure, providing an incidence factor of $1.10 \%$. Three cases $(75 \%)$ had no earlier symptom/history of complexity in producing semen on requirement. Even Recommendation of 50 $\mathrm{mg}$ Vardenafil /Sildenafil citrate and the couples watching sexually stimulating videos did not remedy the situation. Surgical sperm retrieval was successful in case 1. It yielded no live sperm sample in case 2. Cases 3 and 4 had repeat IVF cycles. The male partners were not aware that oocyte retrieval would take place the next day and produced semen within a couple of hours.

Conclusion: Anxiety and psychogenic stress most likely played a major role in these reported cases.

Key: It is hoped that liquid nitrogen for cryopreservation would be the more readily available and easy technique to adopt in such scenarios to be followed for the centres for semen cryopreservation as a necessary prestep towards helping such couples and the upcoming techniques' not widely in practice in developing countries, oocyte vitrification*.

Index Term: Semen Cryopreservation, Ejaculation Malfunction, IVF, ICSI \& Stimulants. 


\section{INTRODUCTION}

The procedure of in vitro fertilization (IVF) can be actually stressful on the couples undergoing treatment emotionally and physically. In our Assisted Reproductive Unit, averages of $350+^{*}$ oocyte retrievals for IVF/ICSI are performed round the year. An ejaculation failure incidence of $1.10 \%$ on the day of oocyte retrieval has occurred between September 2013 to November 2014. Despite of the fact that the female partner is engaged with every day injections, sequential ultrasound scans for the process of oocyte retrieval and successively embryo transfer, however the male partner is called to produce semen for injection/ insemination to the oocytes retrieved (1). Alas, some men are not able to perform out this chore when it doubtless matter most. This is typically an exceptional occurrence with few incidences reports in the literature but for the few to whom it occurs, it can be shattering and upsetting (2).Causes of ejaculation failure in general include the first and foremost reason is the psychological disturbances and nervousness, use of antipsychotics and antidepressant drugs, alcohol, excessive smoking and alcohol drinking (3). There are numerous recommended ways of sperm retrieval for IVF/ICSI in such reported cases $(4,5)$. These include (a) Oral prescription of $50 \mathrm{mg}$ of Vardenafil and sildenafil citrate after an hour of attempted sperm collection (b) Vibrostimulation (c) Vigorous prostatic massage (d) Electroejaculation (e) Percutaneous epididermal sperm aspiration (PESA) ; (f) Testicular sperm aspiration (TESA) ; (g) Testicular sperm extraction (TESE) ; (h) Microsurgical Eppidymal Sperm aspiration (MESA) ; and (i) Sex therapy. At last if these attempts fail the last course of action is the use of donor sperm. If a dilemma is diagnosed, the possibility of cryopreserving sperm for back-up use is always better and carried out prior to initiating the treatment cycle. Here we discussed the four case of ejaculation failure.

\section{Case 1}

Mr. AA was a 44-year serviceman married to a 36 year woman. Their only child was conceived via IVF in 2010. Couple underwent subsequent ICSI cycles were unproductive and futile. However there was no complexly in producing semen during the preceding cycles. Mr AA was asked to go over again for his semen analysis at our unit but he refused as he felt he had done it quite a lot of times in the times of yore and was absolutely normal. His wife had endometriosis and bilaterally blocked tubes. The couple received pre-IVF counselling and commenced treatment in October 2013. Six oocytes were retrieved on the day of oocyte retrieval Mr. AA was unable to produce semen after 4 hour of continuous trying. He attempted masturbation and electro ejaculation and later coitus with his partner with the use of a condom. A $100 \mathrm{mg}$ dose of Sildenafil citrate was prescribed and the clinic staffs calms his restlessness. After $4 \mathrm{~h} .30 \mathrm{~m}$ hour, PESA was successfully performed without the local anaesthesia. Following Intracytoplasmic sperm injection (ICSI), three reduced quality embryos were developed and transferred three days after oocyte retrieval. Which post 15 days appeared us as a negative Beta-Hcg which did not result in a pregnancy.

\section{Case 2}

Mr. AB, was a 39-year IT professional married to a 40- year housewife. They had been married for 15 years with no conception. A previous IVF cycle done in 2010 was unproductive. There was an impediment in sperm production of about $6.00 \mathrm{~h}$ in that particular cycle. Mr. AB. nevertheless had no difficulty with semen production for the analysis. He had normal semen count and parameters. No particular reason was found for the couple's infertility quandary. They had preIVF counselling in particular on the near to the ground success rate using the wife's own eggs as the age and AMH was a critical factor. They opted and preferred to go to the fore using their self eggs. They commenced treatment in December 2013. Eleven oocytes were retrieved. Mr. AB was unable to produce semen for $4.30 \mathrm{~h}$ regardless of watching sexually thought-provoking videos. His anxiety was put to rest and $50 \mathrm{mg}$ Sildenafil citrate was prescribed. He appealed to depart the clinic milieu and produce semen from his residence, a short distance from the clinic. His request was accepted but finally no procurement of sperms. After another $5.30 \mathrm{~h}$, PESA subsequently TESA were attempted, respectively under local anaesthesia, combined with intravenous promethazine and 
pentazocine regrettably, no live sperm cell was recovered and the cycle was futile. They had a repeat cycle six months after, at a standstill preferring to use their own eggs. His semen sample was cryopreserved for this particular cycle as a backup. On the day of oocyte pickup, he still could not produce semen and the frozen sample was employed. Subsequently day 3 transfer of three Grade A embryos, pregnancy occurred.

\section{Case 3}

Mr. AC was a 42-year Govt servant married to a 36-year house wife. She prior had a kid from a different spouse before her present marriage. Her husband parallel had two children from an earlier marriage. They had been unable to achieve a pregnancy after 10 years of nuptials. Mr.AC had no problem with semen production for analysis and his sperm count was 30 million cells $/ \mathrm{ml}$ they had pre-IVF counselling and have the same opinion to use donor oocytes. Following IVF treatment in Jan 2014, twelve oocytes were retrieved from the donor. Mr. AC could not produce semen after $3 \mathrm{~h}$ of struggle with the aid of sexually provoking videos. Sildenafil citrate, $50 \mathrm{mg}$ was prescribed, his anxiety allayed and he had coitus interrupt us with his wife. Semen sample could still not be reproduced. He refused any surgical procedure and the cycle was cancelled. They had a repeat cycle in March 2014. The husband was not agreeable with the employ of cryopreserved sperms, as he was not convinced it would result in a "normal baby". In conformity with the wife, a pronouncement was taken to get the husband to produce semen a day previous to oocyte pickup while informing him it was to be for future use. Mr. AC. succeeded in producing semen within an hour. Following ICSI of five oocytes, three Grade A embryos were transferred on day 2. Pregnancy test taken two weeks later was positive. A twin baby delivered.

\section{Case 4}

Mr. AD was a 32-year businessman, married to a 28 -year housewife. She had 1 previous premarital terminations of pregnancy . They had been unable to accomplish a pregnancy after one year unprotected intercourse of marriage. Mr. AD produced semen without difficulty for analysis. Semen parameters were usual and normal. Pre-IVF counselling was offered to the couple, but refused. They commenced IVF treatment in October 2013. Seven metaphase 2 oocytes were procured. Mr. AD could not produce semen after $4 \mathrm{~h}$. He was reassured and given $50 \mathrm{mg}$ of viagra, which he disallowed. He opted to go his address and produce semen and assured to be back within an hour. He was advised to bring the semen sample within half an hour of collection and asked to inform back to the clinic if he still experience complication. After another $4 \mathrm{~h}$, efforts were made at reaching the couple but they had switched off their contact numbers. The cycle was eventually cancelled by the end of that day. A repeat cycle was carried out four months later. They accepted pre-IVF counselling because of the previous experience, this cycle semen cryopreservation was accepted done at time, Mr. AD was not informed that the wife had commenced controlled ovarian hyperstimulation. He produced semen within an hour, which was inseminated with his wife's oocytes. No pregnancy resulted.

\section{DISCUSSION AND CONCLUSION}

Four cases of unexpected ejaculation malfunction occurred during the 1-year period at our assisted reproduction centre. A total of 362 oocyte pickup cycles were carried out during the period, given an incidence of $1.11 \%$. This is to a certain extent high report as we consider from other centres divulge it is a very rare occurrence $(6,7)$. However Emery et al described only five cases over a 4 year period with an average oocyte retrieval cycle of 500 per year (7). The raison d'être for our high prevalence may not be unbelievable. Contrasting in the Western developed world, parenthood appears to have more and arguably, profound roots in Indian hamlet $(8,9)$. In the typical Indian society, children secure conjugal ties, offer social security, assist with labour, confer social prominence secure rights of assets and inheritance, endow with continuity through re-incarnation and maintaining the family lineage and satisfy emotional needs (8). Case 1 had no prior history of ejaculation failure as he had no problems in producing semen on demand in the clinic during his 
previous IVF attempts. While case 2 had a six hour interruption prior to producing semen in a preceding IVF cycle, he had no malfunctions with semen production on requirement in the assisted reproduction centre for analysis, just like cases 3 and 4 . This shows that acute ejaculation failure can transpire in patients who prior had no difficulty with semen production on request in the clinic. Sildenafil citrate (Viagra) has been recommended at different dose after unsuccessful trials of more than $2 \mathrm{~h}$ to produce semen (10). At the same time as this has been successfully used in a few of our patients, it did not yield the desired effect in the three cases in which it was prescribed earlier. Surgical sperm procurement in the form of PESA and TESA have equally being used in such cases to gain spermatozoa $(11,12)$. While PESA was successfully done in case 1 , both TESA and PESA were unsuccessful in retrieving any live sperm in case 2. Case 3 refused any surgical procedure. However for the next procedure semen was cryopreserved and pregnancy occurred earlier which he denied as he believed cryopreserved semen will not result in a normal child. It is our standard practice to counsel the couples to abstain from sexual intercourse for 3-4 days prior to oocyte pickup. In all the cases psychogenic anejaculation on the day of oocyte retrieval played a vital role. Anxiety has been shown in infertile couples to be the vast psychological manifestation, allied to the stressful nature of IVF and the apprehension of failure (13). This is doubtless more manifested on the day of oocyte retrieval. Therefore the case 4 have not been updated of the exact day or time of oocyte retrieval that might have allayed their anxiety. Saleh and colleagues (14) collected data from 405 men with normal sexual function. All of them obtained a first semen sample devoid of difficulty. After being notified that the analysis of their semen sample was abnormal, 11\% (46/405) failed to get hold of sperm by masturbation two weeks later. This psychogenic sexual dysfunction followed severe anxiety, which increased in such men. There is however ethical dilemma involved in this practice which most likely would not be suitable in industrialized countries. While the equipments needed for cryopreservation of semen is much cheaper contrast to the equipments required for IVF, availability and sustainability of liquid nitrogen is often times a luxury in our environment. The women are usually stigmatized, leading to seclusion, neglect, domestic aggression or they may end up as second wives in a polygamous marriage, while the husbands might be denied their rightful legacy $(15,16,17)$. When all the possible modus operandi of obtaining sperm fails, the existing options would be to use donor sperms or cancel the treatment and cryopreserve sperms for use in subsequent cycle. In our assisted reproduction centre, we frequently will not use donor sperms except this had been discussed and agreed upon much prior with the couples. In conclusion, although ejaculation failure on the day of oocyte retrieval is an atypical incidence, it is a foremost cause for apprehension in our practice. Anxiety most likely played a vital role in these stated cases. Even though there are ethical dilemmas, not divulging the definite date of oocyte retrieval to the male partner believing at risk of unexpected ejaculation failure might be correlated with reduced anxiety and therefore aid semen production. It is on the other hand hoped that liquid nitrogen for cryopreservation would become more readily accessible in India so that more centres can implement and adopt semen cryopreservation as an essential step towards assisting such couples.

\section{Acknowledgements}

Express gratitude to Dr T S Muralidhar, our colleagues for the clinical data compilation for all of their work toward the study, data collection and review.

\section{References:}

[1] Elliott S (1993) Anejaculation, fertility and sex. Can J Hum Sex 2,121-127.

[2] Hammer-Burns L and Covington SN (eds) (1999) Infertility Counseling. A Comprehensive Handbook for Clinicians. Parthenon, London and New York.

[3] Hovav Y, Kafka I, Horenstein E and Yaffe H (2000) Prostatic massage as a method for obtaining spermatozoa in men with psychogenic anejaculation. Fertil Steril 74,184-185. 
[4] Fahmy I, Kamal A, Metwali M, Rhodes C, Serour G, Aboulghar M. Vigorous prostatic massage: a simple method to retrieve spermatozoa for intracytoplasmic sperm injection in psychogenic anejaculation. Case report. Hum Reprod 1999;14(8):2050-3.

[5] Jannini EA, Simonelli C and Lenzi A (2002a) Disorders of ejaculation. J Endocrinol Invest 25,1006-1009.

[6] Jannini EA, Simonelli C and Lenzi A (2002b) Review. Sexological approach to ejaculatory dysfunction. Int J Androl 25,317-323.

[7] Lin YH, Hwang JL, Tsai YL. Percutaneous epididymal sperm aspiration in psychogenic anejaculation during IVF. A report of two cases. J Reprod Med 1999;44(10):894-6.

[8] Emery M, Senn A, Wisard M, Germond M. Ejaculation failure on the day of oocyte retrieval for IVF. Case report. Hum Reprod 2004;19(9):2088-90.

[9] Dyer SJ. The value of children in African countries - insights from studies on infertility. J Psych Obstet Gynecol 2007;28(2): 69-77.

[10] Okonofua FE, Harris D, Odebiyi A, Kane T, Snow RC. The social meaning of infertility in Southwest Nigeria. Health Trans Review 1997;7:205-20.

[11] Tur-Kaspa I, Segal S, Moffa F, Massobrio M, Meltzer S. Viagra for temporary erectile dysfunction during treatment with assisted reproductive technologies: case report. Hum Reprod 1999;14(7): 1783-4.

[12] Belker AM, Sherins RJ, Dennison-Lagos L, Thorsell LP, Schulman JD. Percutaneous testicular sperm aspiration: a convenient and effective office procedure to retrieve sperm for in vitro fertilization with intracytoplasmic sperm injection. J Urol 1998;160(6):2058-62.

[13] Golombok S. Parenting: what really counts? Philadelphia: Routledge, Taylor and Francis; 2000.

[14] Saleh RA, Ranga GM, Raina R, Nelson DR, Agarwal A. Sexual dysfunction in men undergoing infertility evaluation: a cohort observational study. Fertil Steril 2003;79(4):90912.

[15] Van Balen F, Gerritis T. Quality of infertility care in poorresource areas and the introduction of new reproductive technologies. Hum Reprod 2001;16(2):215-9.

[16] Ombelet W, Campo R. Ethics, research, legal, counseling: affordable IVF for developing countries. RBMOnline 2007; 15(3):257-65.

[17] Ameh N, Kene TS, Onuh SO, Okohue JE, Umeora OU, Anozie OB. Burden of domestic violence amongst infertile women attending infertility clinics in Nigeria. Niger $\mathrm{J}$ Med 2007;16(4):375 